\title{
BM] Global Health Ethnic minority status as social determinant for COVID-19 infection, hospitalisation, severity, ICU admission and deaths in the early phase of the pandemic: a meta-analysis
}

To cite: Agyemang C, Richters A, Jolani S, et al. Ethnic minority status as social determinant for COVID-19 infection, hospitalisation, severity, ICU admission and deaths in the early phase of the pandemic: a metaanalysis. BMJ Global Health 2021;6:e007433. doi:10.1136/ bmjgh-2021-007433

Handling editor Seema Biswas

- Additional supplemental material is published online only. To view, please visit the journal online (http://dx.doi.org/10. 1136/bmjgh-2021-007433)

$\mathrm{CA}$ and $\mathrm{AR}$ contributed equally.

$\mathrm{CA}$ and $\mathrm{AR}$ are joint first authors.

Received 16 September 2021 Accepted 26 0ctober 2021

\section{Check for updates}

(c) Author(s) (or their employer(s)) 2021. Re-use permitted under CC BY-NC. No commercial re-use. See rights and permissions. Published by BMJ.

For numbered affiliations see end of article.

\section{Correspondence to} Charles Agyemang; c.o.agyemang@amsterdamumc. $\mathrm{nl}$

\section{ABSTRACT}

Introduction Early literature on the COVID-19 pandemic indicated striking ethnic inequalities in SARS-CoV-2related outcomes. This systematic review and metaanalysis aimed to describe the presence and magnitude of associations between ethnic groups and COVID-19-related outcomes.

Methods PubMed and Embase were searched from December 2019 through September 2020. Studies reporting extractable data (ie, crude numbers, and unadjusted or adjusted risk/ORs) by ethnic group on any of the five studied outcomes: confirmed COVID-19 infection in the general population, hospitalisation among infected patients, and disease severity, intensive care unit (ICU) admission and mortality among hospitalised patients with SARS-CoV-2 infection, were included using standardised electronic data extraction forms. We pooled data from published studies using random-effects metaanalysis.

Results 58 studies were included from seven countries in four continents, mostly retrospective cohort studies, covering a total of almost 10 million individuals from the first wave until the summer of 2020. The risk of diagnosed SARS-CoV-2 infection was higher in most ethnic minority groups than their White counterparts in North American and Europe with the differences remaining in the US ethnic minorities after adjustment for confounders and explanatory factors. Among people with confirmed infection, African-Americans and Hispanic-Americans were also more likely than White-Americans to be hospitalised with SARS-CoV-2 infection. No increased risk of COVID-19 outcomes (ie, severe disease, ICU admission and death) was found among ethnic minority patients once hospitalised, except for a higher risk of death among ethnic minorities in Brazil.

Conclusion The risk of SARS-CoV-2 diagnosis was higher in most ethnic minorities, but once hospitalised, no clear inequalities exist in COVID-19 outcomes except for the high risk of death in ethnic minorities in Brazil. The findings highlight the necessity to tackle disparities in social determinants of health, preventative opportunities and delay in healthcare use. Ethnic minorities should

\section{Key questions}

What is already known?

- Early literature on the COVID-19 pandemic indicated striking ethnic inequalities in SARS-CoV-2-related outcomes. This systematic review and meta-analysis aimed to describe the presence and magnitude of associations between ethnic groups and COVID-19related outcomes.

What are the new findings?

- The risk of SARS-CoV-2 diagnosis was higher in most ethnic minorities, but once hospitalised, no clear inequalities exist in COVID-19 outcomes except for the high risk of death in ethnic minorities in Brazil.

What do the new findings imply?

- The findings highlight the necessity to tackle disparities in social determinants of health, preventative opportunities and delay in healthcare use. Ethnic minorities should specifically be considered in policies mitigating negative impacts of the pandemic.

specifically be considered in policies mitigating negative impacts of the pandemic.

PROSPERO registration number CRD42020180085.

\section{INTRODUCTION}

The COVID-19 pandemic caused by SARSCoV-2 has exposed global health inequalities. Data on ethnic minorities mainly from the USA and UK have shown striking ethnic inequalities in diagnosis of SARS-CoV-2 infection and related outcomes. ${ }^{1-3}$ In both USA and UK, a disproportionate number of SARS-CoV-2 infections, hospital critical cases and deaths are occurring among ethnic minority groups. 
The UK's Intensive Care National Audit and Research Centre (ICNARC) report, for example, shows that about third of critically ill COVID-19 patients during the early phase of the pandemic were from ethnic minority background despite ethnic minority groups being about $14 \%$ of the UK population. ${ }^{2}$ Data from the USA also show that African-Americans and Hispanic-Americans account for a disproportionate share of COVID-19-related infection, hospitalisation and deaths relative to their representation in the population. ${ }^{45}$

Recently, some meta-analyses on COVID-19 among ethnic minority groups have been published. ${ }^{67}$ However, these earlier works have several limitations including reliance on non-peer-reviewed papers, combined heterogeneous ethnic groups such as South Asians and East Asians and African descent populations living in different geographical locations, and were limited to the earliest phase of the pandemic. ${ }^{6}$ Given the impact of social determinants of health on COVID-19 disease and its related outcomes, which vary importantly between world regions, it is critically important to evaluate in detail COVID-19 infection and its related outcomes among the heterogeneous ethnic groups living in different parts of the world to guide targeted prevention and treatment to reduce ethnic inequalities in health.

We therefore conducted a meta-analysis to quantify the risk ratio (RRs) between ethnic minority groups and the major populations living in different parts of the world on five commonly reported COVID-related outcomes including (1) confirmed SARS-CoV-2 infection among the general population; (2) hospitalisation among COVID-19 patients with a confirmed infection; (3) severe COVID-19 disease among hospitalised patients with a confirmed infection; (4) intensive care unit (ICU) admission among hospitalised patients with a confirmed COVID-19 infection and (5) death among hospitalised patients with a confirmed COVID-19 infection across world regions.

\section{METHODS}

This systematic review and meta-analysis was conducted in accordance with the Preferred Reporting Items for Systematic reviews and Meta-Analyses extension for Scoping Reviews guideline. ${ }^{8}$ The protocol results on age and sex for the early phase of the pandemic have been published. $^{9}$

\section{Search strategy and selection criteria}

The search strategy was developed with a specialised librarian (GF) support. Medline via PubMed and EMBASE databases were searched from December 2019 to 17 September 2020. The COVID-19 term was elaborated in combinations of controlled vocabulary and freetext terms (Appendix 1: Search strategy). Only studies reported in English were considered.

All papers were screened for the presence of data on any of the demographic factors (ie, age, gender and ethnicity) in combination with any of the COVIDoutcomes that we considered as reported in the preregistration on Prospero in the general population and hospitalised patients. Initial screening on the basis of title and abstract of eligible studies was carried out by allocating subsets of the search results to all members of the review team. In a preceding report on the demographic factors of age and sex, the estimated between-reviewer agreement on a random sample of 500 studies was $98.4 \%$ with a kappa of 0.74 , indicating substantial agreement in this review team. ${ }^{9}$ When the information in the abstract did not suffice or if there was any doubt, the studies remained potentially eligible.

Studies were included if they met the following inclusion criteria: (1) focused on humans, (2) included any of the predefined COVID-19 or SARS-CoV-2 coronavirusrelated outcomes, (3) reported on multiple ethnic/racial groups, (4) contained raw data that allowed calculation of ORs or contained calculated (unadjusted or adjusted) RRs or ORs for our prespecified associations (online supplemental appendix table 1). We considered adjusted estimates for age, age and sex, or a larger set of adjustment factors. Studies were excluded if no valid comparisons across ethnic groups could be made, or focussed on specific populations (eg, healthcare workers) alone or were based on patients who were admitted to hospital indications other than SARS-CoV-2 infection.

\section{Data analysis}

Data were extracted from included studies regarding patient demographics, study characteristics and the severity stages of COVID-19 including infection, hospitalisation, disease severity, ICU admission and death in a predefined electronic data sheet. Categorisation of severe disease was extracted as used in the original studies, which used the WHO guidance ${ }^{10}$ in almost all cases. This was double-checked by a second reviewer and any disagreements were resolved by consensus or by consulting a referee. Additionally, the inclusion and data extraction of all studies that were potential outliers as visually identified on the forest plots were double-checked. Risk of bias of the included studies was appraised using the Newcastle Ottawa Scale (NOS).$^{11}$

Meta-analysis was performed to determine the pooled effect sizes with corresponding 95\% CIs and (in case of heterogeneity) $95 \%$ prediction intervals using randomeffects model. ${ }^{12}$ The unadjusted ORs were calculated from crude numbers. For studies that reported ORs or RRs that were adjusted for age, age and sex, or larger adjustment set, we synthesised ORs according to COSMOS-E. ${ }^{13}$ These studies typically adjusted for different sets of factors, but age, sex and comorbidities were the most common covariates in the models (online supplemental appendix table 2). White ethnicity was considered as the reference group for the comparisons, as this was the dominant ethnic group in all included studies except two studies from Asia, where reference groups mentioned by the original studies were used. 
Because of the huge differences in migration histories, healthcare systems and access to healthcare and services between countries, we stratified our analyses by world regions rather than combining all ethnic groups living in different geographical locations. Thus, we stratified our pooled analyses by North America, Europe and South America where data were identified. For the ethnic groups, we distinguished South Asians from other Asians where data were provided due to important differences between these groups in terms of health outcomes, ethnicity and socioeconomic status (SES).$^{14}$

We explored sources of statistical heterogeneity through visual inspection of the forest plots and by calculating $\mathrm{I}^{2}$ statistics. ${ }^{15}$ We assessed the presence of publication bias by constructing funnel plots for visual inspection and statistically tested potential asymmetry using the Egger and Harbord test when at least eight studies were available per ethnic group comparison. ${ }^{15} 16$ A trim-andfill method and cumulative meta-analyses was used to explore the magnitude and direction of publication bias in case of asymmetry. All meta-analyses were conducted using Stata V.14.1 (StataCorp, USA), and p-values $<0.05$ considered statistically significant.

\section{Role of the funding source}

There was no funding source for this study.

\section{RESULTS}

\section{Study selection}

The titles and abstracts of 21710 papers were screened. Full text was reviewed of 914 papers, of which 101 contained data on ethnicity. Ultimately, 58 papers contained extractable data on both ethnicity and at least one of the five outcomes included in the meta-analysis (figure 1).

\section{Study characteristics}

The 58 included papers contained data on study populations from four continents, reporting on a total of 9918 103 individuals (table 1$)$. The majority of papers $(n=41)$ were from the USA, 13 papers were from Europe (10 from UK, 2 from Spain and 1 from Italy); 2 papers from Brazil and 1 paper each from Singapore and Thailand. Most studies were retrospective cohort studies and most reported outcomes were diagnosed infections among the general population and death among hospitalised patients. The sample size ranged from 50 to 8.2 million people. Indicators of ethnicity were based on self-report, medical records and physician determination, while others did not report the indicators used.

\section{Risk of confirmed SARS-CoV-2 infection among the general population}

The summary of pooled unadjusted and adjusted ORs for SARS-CoV-2 infection in the USA, stratified by ethnicity is shown in figure 2. The pooled unadjusted ORs were significantly higher in African-Americans ( $\mathrm{OR}=1.94 ; 95 \%$ CI, 1.58 to 2.38, 13 studies) and Hispanic-Americans
(2.44; 1.87 to $3.20,10$ studies), but not in Asian-Americans (1.33; 0.95 to $1.88,7$ studies), Native Hawaiians (1.53; 0.91 to $2.57,4$ studies) and American-Indians (0.80; 0.44 to $1.44,4$ studies) compared with White-Americans (online supplemental appendix figure 1). Moreover, there were mixed levels of heterogeneity across all ethnic group comparisons $\left(\mathrm{I}^{2}: 42 \%-97 \%\right.$ ) (online supplemental appendix figure 1). Pooled adjusted ORs from studies that reported ORs adjusted for multiple factors such as age, sex, SES and comorbidities (online supplemental appendix table 2) were higher in African-Americans (2.74; 1.47 to 5.10, 3 studies), Hispanic-Americans (2.87; 2.13 to $3.86,1$ study) and Asian-Americans (1.74; 1.16 to 2.61, 2 studies) than in White-Americans, but not in American Indians $(0.63 ; 0.36$ to $1.11,1$ study) and Native Hawaiians (1.02; 0.66 to $1.57,1$ study) (online supplemental appendix figure 2).

In Europe, all the studies on SARS-CoV-2 infections were carried out in the UK. The pooled unadjusted ORs were higher in African-Caribbean/Black-Africans (2.22; 1.68 to $2.92,6$ studies), South-Asians $(1.91 ; 1.34$ to 2.73 , 4 studies), Mixed-race $(1.35 ; 1.27$ to $1.44,5$ studies $)$ and other Asians (2.11, 1.95 to 2.28, 1 study), but not among Asians (1.25; 0.53 to $2.90,4$ studies) compared with Whites (online supplemental appendix figure 3). Four studies on African-Caribbean/Black-Africans and two studies on Asians and two studies on South-Asians provided data with adjustments for multiple factors, where only AfricanCaribbean/Black-Africans had a statistically significant higher risk of infection in pooled adjusted ORs (online supplemental appendix figure 4). One study in Singapore found a higher unadjusted risk of COVID-19 infections among people with Chinese ethnicity and one study in Thailand found no difference in unadjusted risk of COVID-19 infection between people with Thai and other ethnicity.

\section{Risk of hospitalisation among COVID-19 patients}

All but one study on hospitalisations were carried out in the USA. The summary of pooled unadjusted and adjusted risk of COVID-19 hospitalisation, stratified by ethnicity is shown in figure 3 . Thirteen studies on African-Americans, six studies on Asian-Americans and six on Hispanic-Americans provided unadjusted effect estimates on hospitalisation with COVID-19 disease. The pooled unadjusted risk was significantly higher only in African-Americans compared with White-Americans (online supplemental appendix figure 5). Two studies in African-Americans, one in Asian-Americans and three in Hispanic-Americans provided data on age-adjusted rates. The pooled age-adjusted ORs show no statistically significant differences between the ethnic groups except for Asian-Americans where only one age-adjusted study was available. The pooled ORs of hospitalisation adjusted for multiple factors including age, sex, SES and comorbidities were significantly higher in African-Americans (1.53; 1.23 to $1.89,9$ studies $)$ and Hispanic-Americans $(2.08 ; 1.60$ to $2.70,5$ studies) and in Asian-Americans (1.59; 1.14 to 

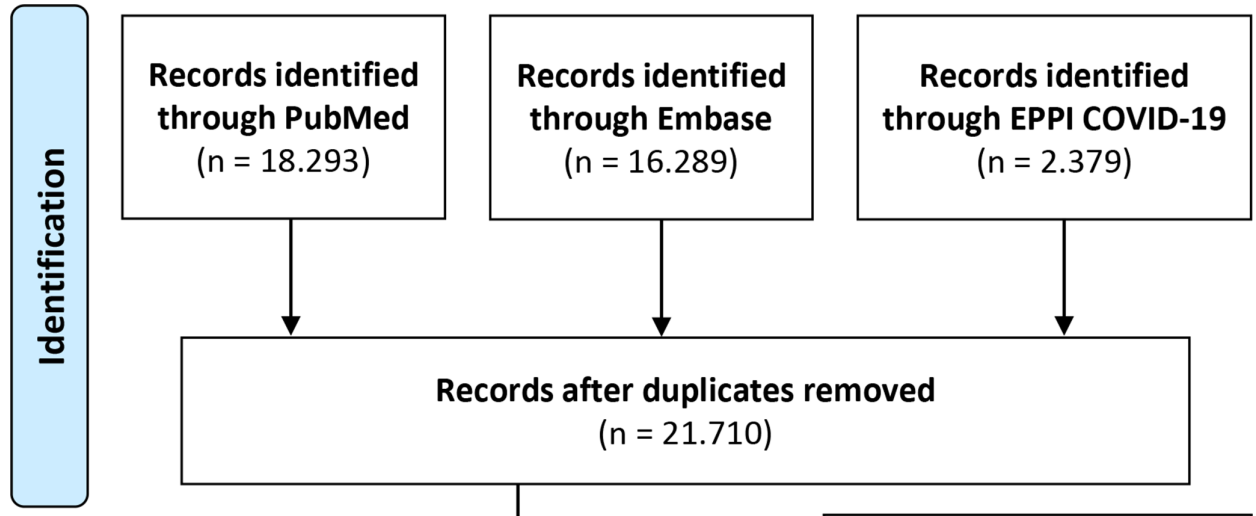

( $n=16.289$ )
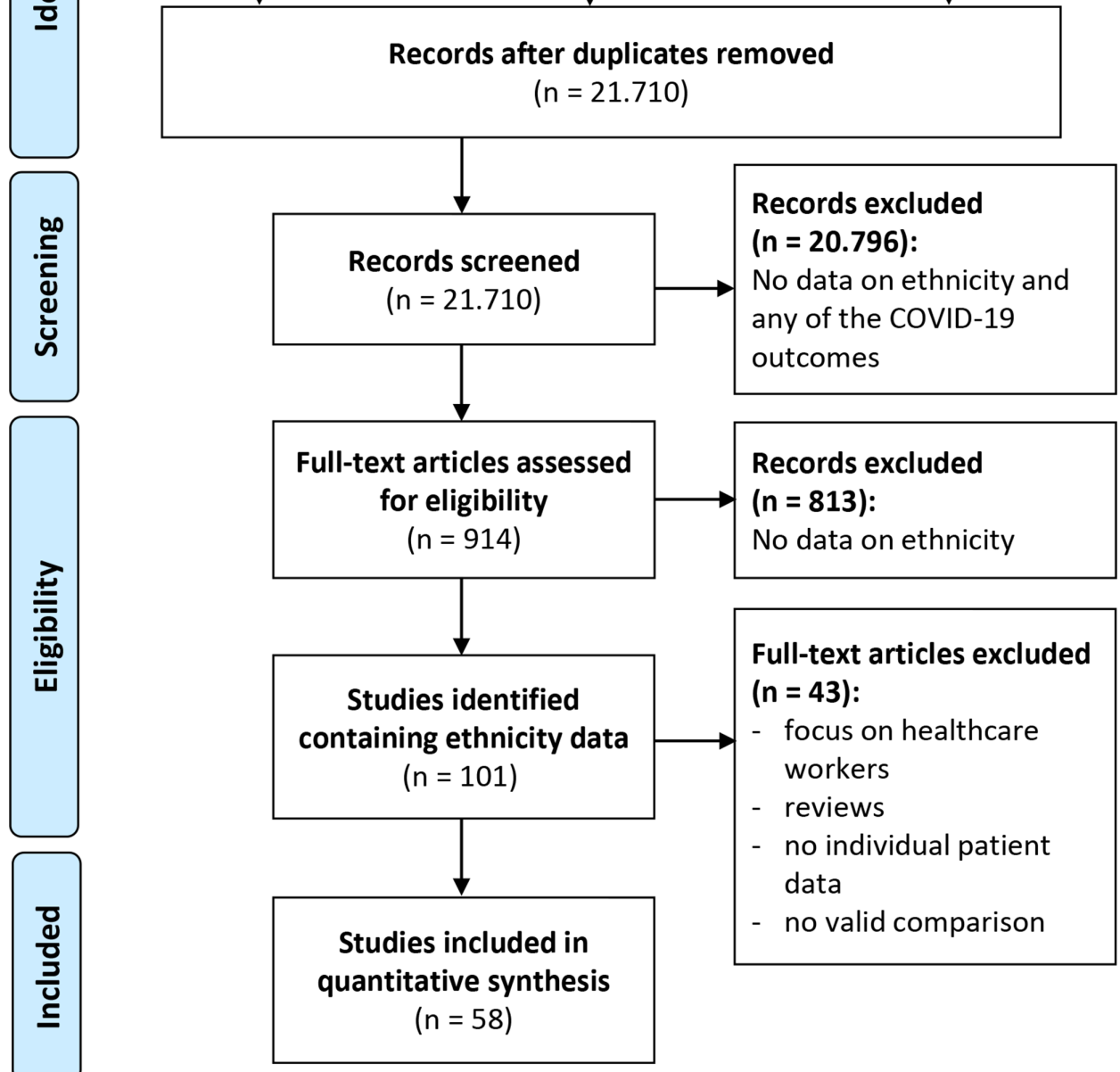

Records excluded

( $n=813$ ):

No data on ethnicity

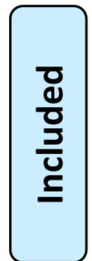

Full-text articles excluded

( $n=43$ ):

- focus on healthcare

workers

- reviews

- no individual patient

data

- no valid comparison

Figure 1 Flow diagram for assessment of eligible studies in the systematic review and meta-analysis. EPPI Centre (COVID-19: a living systematic map of the evidence) was consulted up to 31 March 2020 (available through https://eppi.ioe.ac.uk/ COVID19_MAP/covid_map_v5.html).

2.23, 4 studies) compared with White-Americans (online supplemental appendix figure 6). One study from Brazil provided data on hospitalisation among ethnic groups and found a higher rate of hospitalisation among Asian, indigenous or unknown ethnicity, but not among AfroBrazilians/mixed race compared with White-Brazilians in both unadjusted and adjusted rates. ${ }^{17}$

\section{Severe COVID-19 disease among hospitalised patients}

All studies on severity of the COVID-19 disease were carried out in the USA. The summary of pooled unadjusted and adjusted analyses for COVID-19 severity among hospitalised patients, stratified by ethnicity is shown in figure 4. Eight studies on African-Americans, six studies on Hispanic-Americans and three studies on Asian-Americans reported unadjusted effect estimates on COVID-19 severity among hospitalised patients and the pooled ORs showed no significant differences between ethnic groups, except for a higher risk in Asian-Americans $(3.10 ; 1.83$ to 5.26$)$ (online supplemental appendix figure $7)$. The level of heterogeneity was moderate for AfricanAmericans $\left(\mathrm{I}^{2}=68 \%\right)$ and Hispanic-Americans $\left(\mathrm{I}^{2}=59 \%\right)$, but not for Asians. No sign of asymmetry was found based on the funnel plots. Three studies on African-Americans and two studies on Hispanic-Americans adjusted for multiple factors, but severity of disease did not differ between the ethnic groups in the pooled data (online supplemental appendix figure 8).

\section{Admission to ICU among hospitalised COVID-19 patients}

All studies on admission to ICU were conducted in the USA. The summary of pooled unadjusted and adjusted rates for admission to ICU, stratified by ethnicity is shown in figure 5. Eight studies on African-Americans, three 

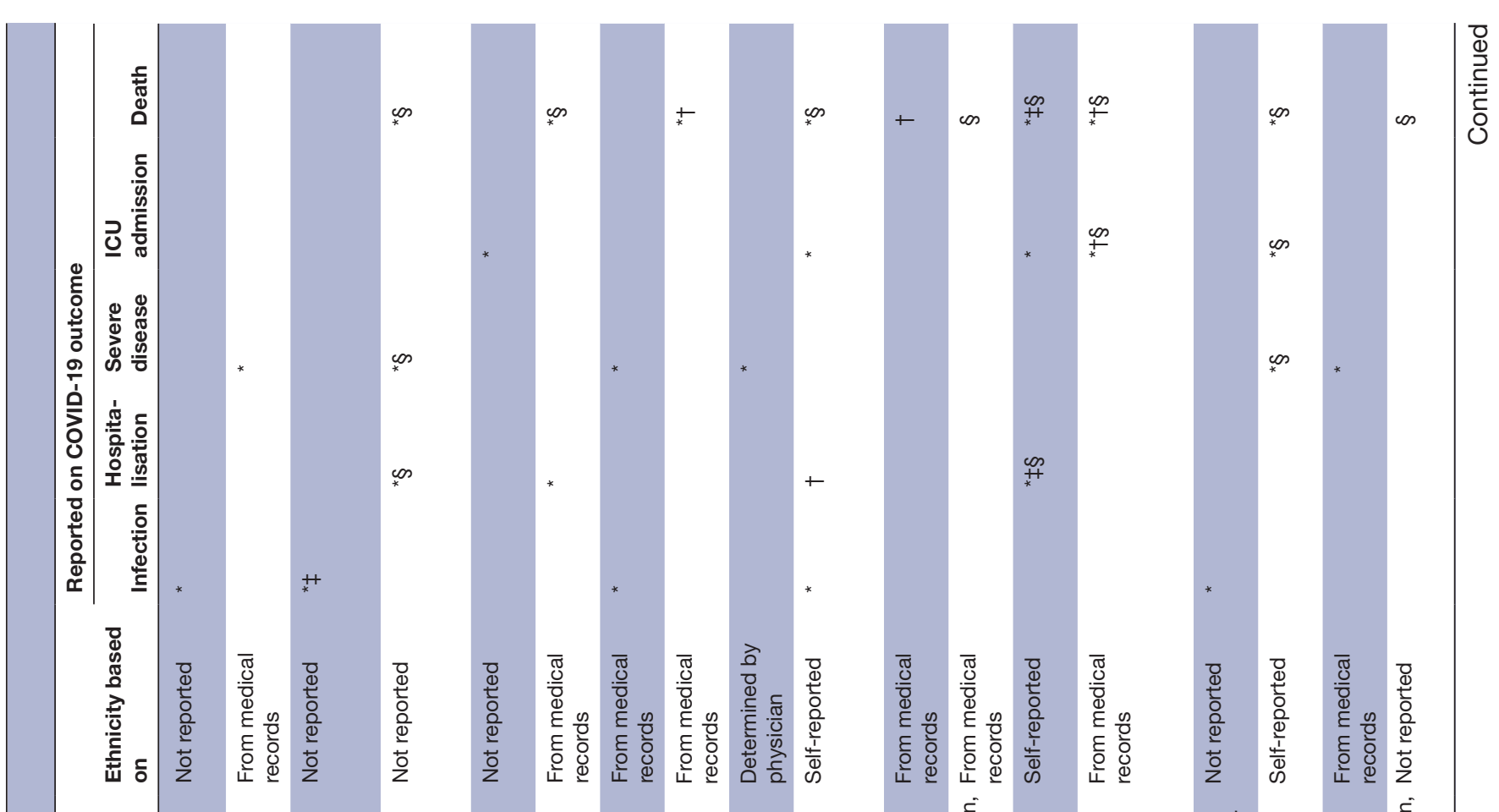

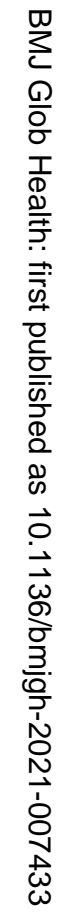

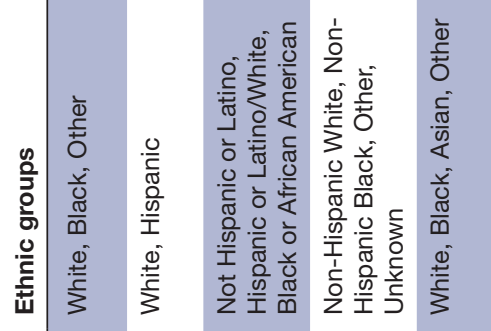

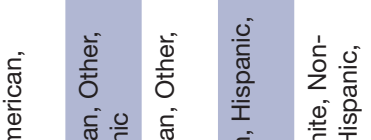

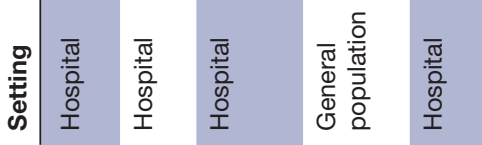

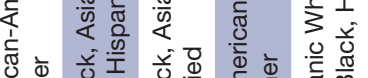

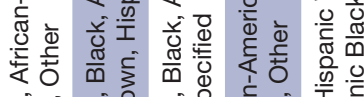

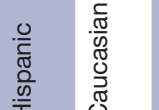

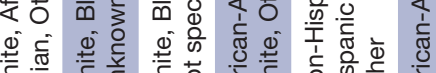

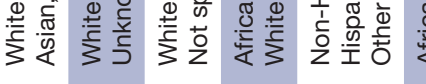

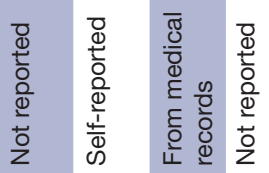

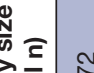
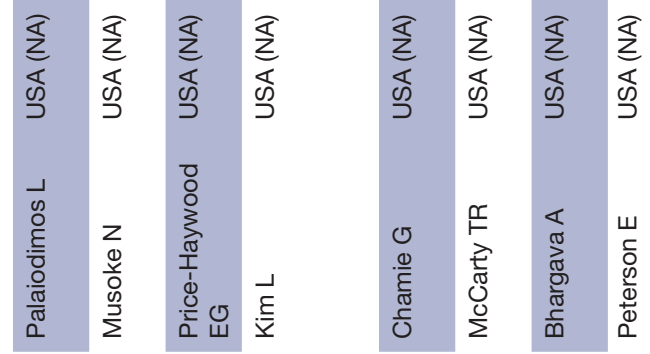

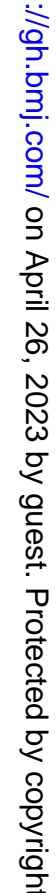




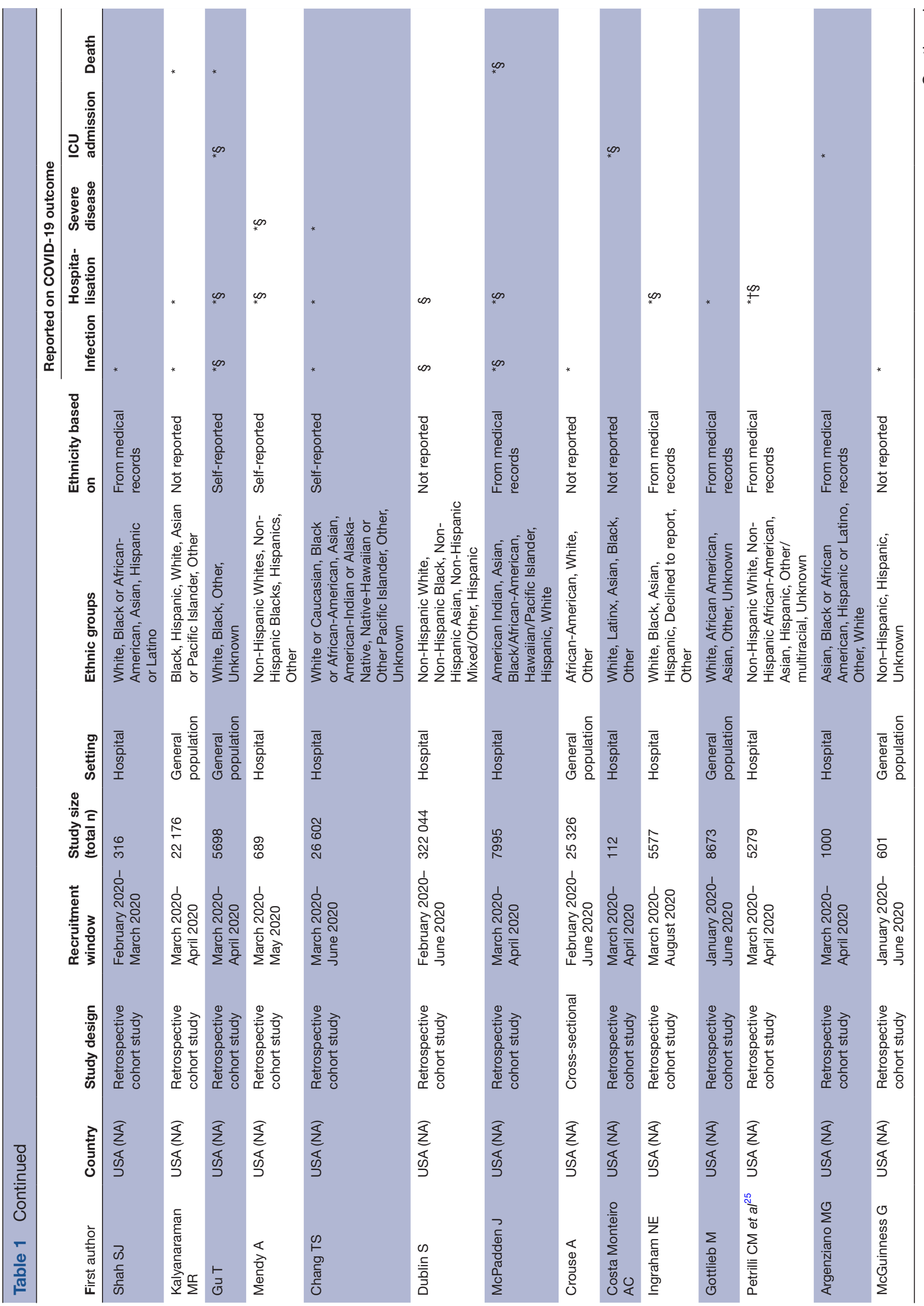




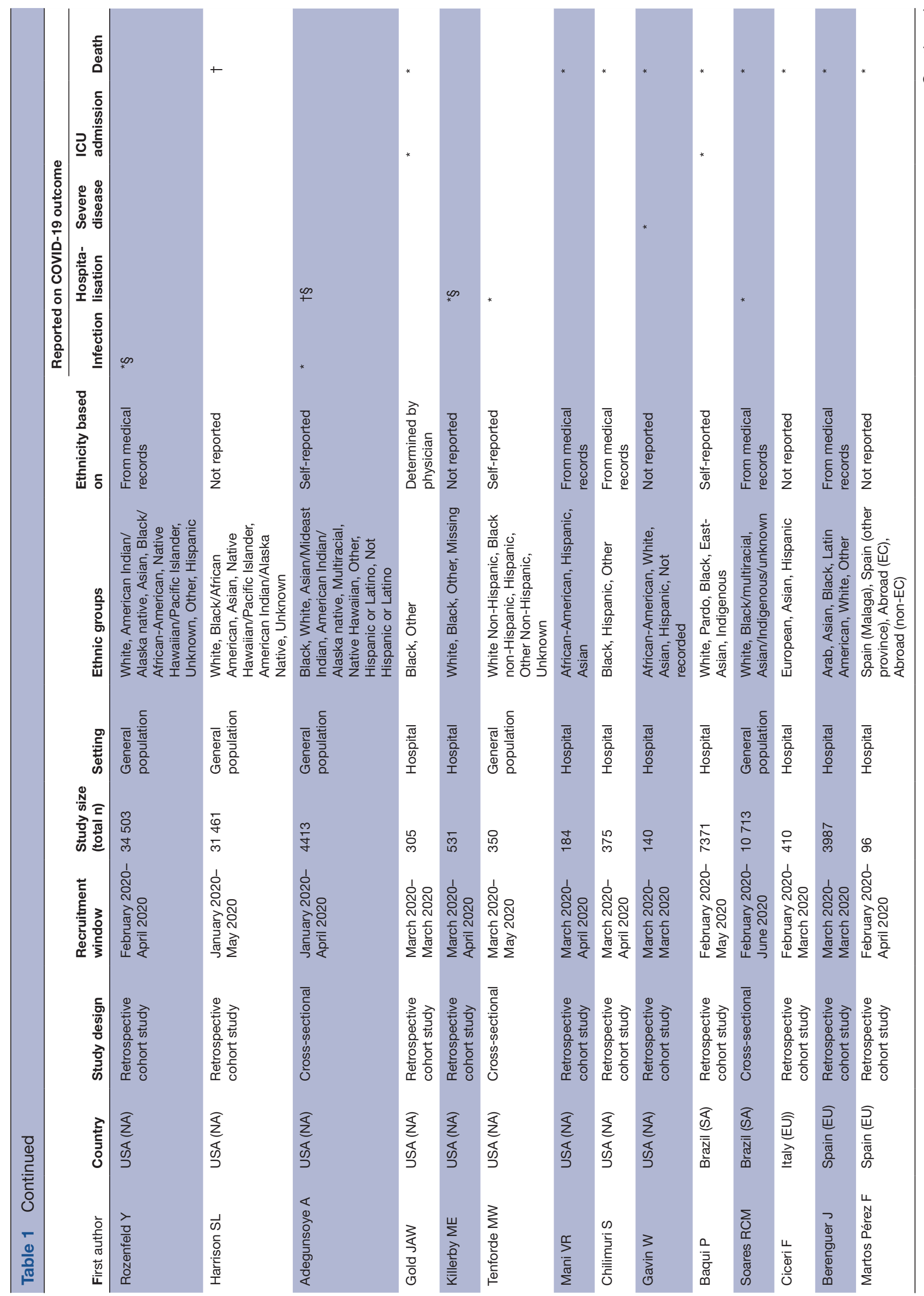




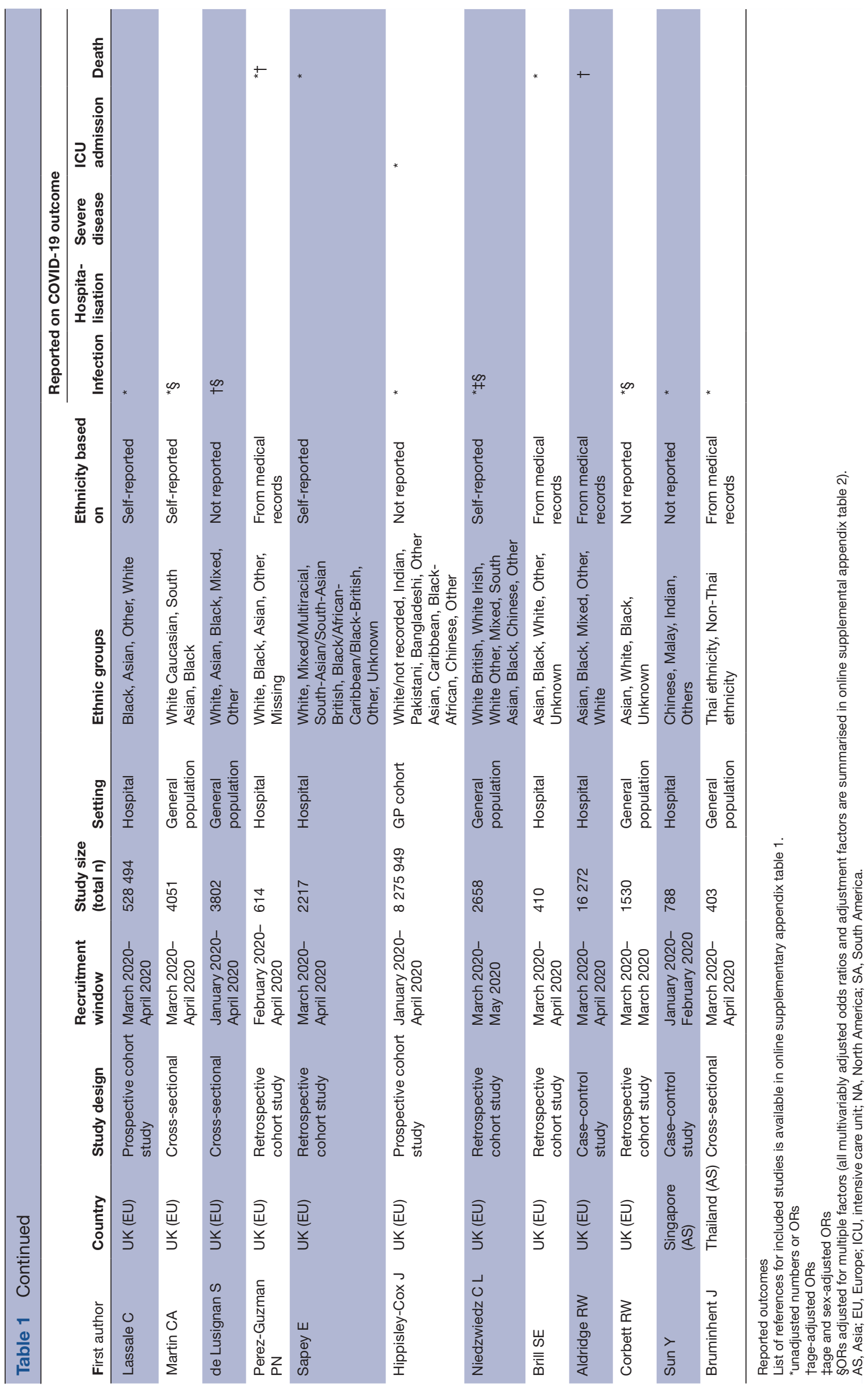


Reference: White American

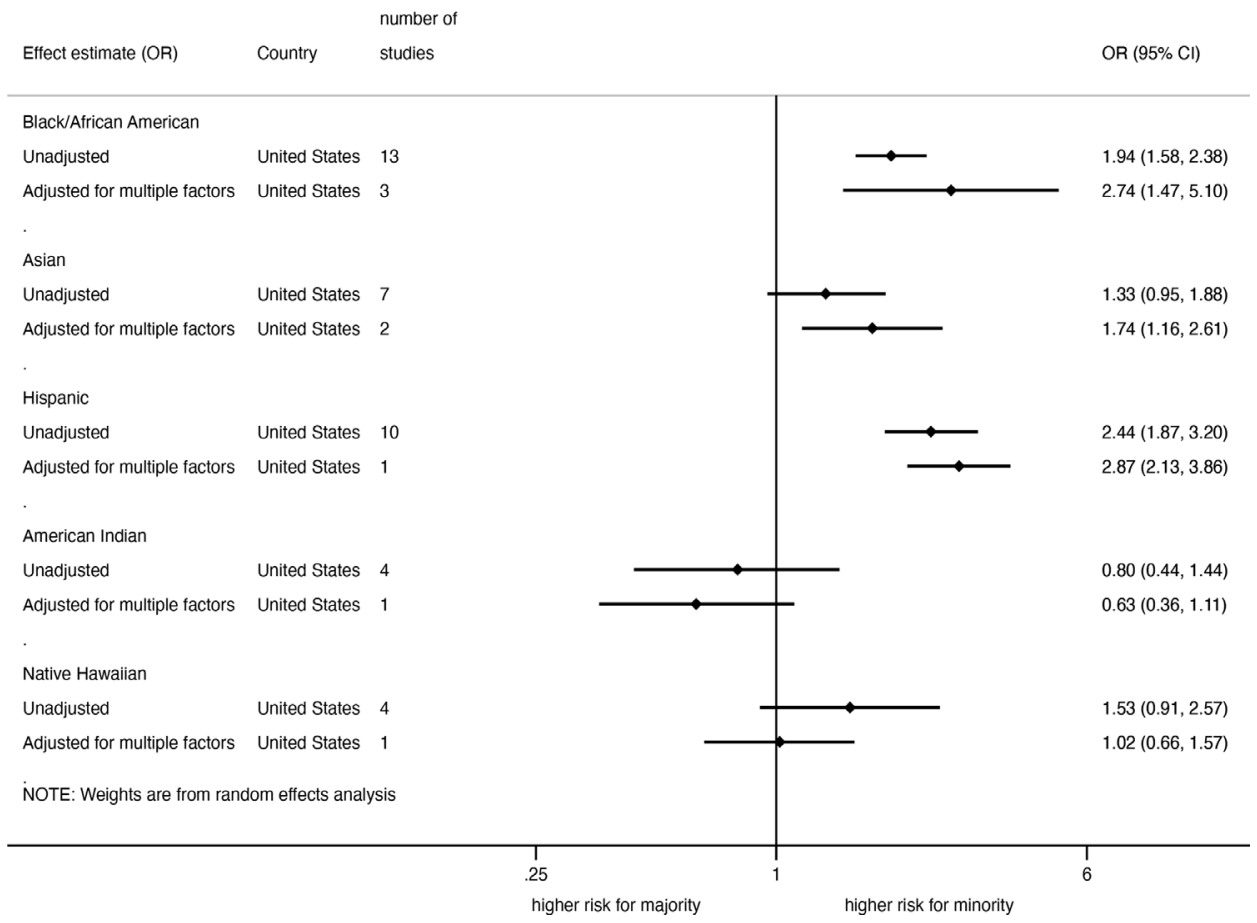

Figure 2 Pooled unadjusted and adjusted risk of SARS-CoV-2 infection among the general population in the USA.

studies on Asian-Americans and five studies on HispanicAmericans provided unadjusted effect estimates on ICU admissions among hospitalised COVID-19 patients and the pooled analysis showed no statistically significant differences across ethnic groups except for AsianAmericans that had a higher risk of admission to ICU compared with the White-Americans (1.92; 1.02 to 3.62) (online supplemental appendix figure 9 ). There was only a moderate level of heterogeneity for Hispanic-Americans $\left(\mathrm{I}^{2}=57 \%\right)$. One study each with African-Americans and Hispanic-Americans provided data on age-adjusted rates and none found a significant difference between the ethnic groups. Four studies on African-Americans, three studies on Hispanic-Americans and one study on Asian-Americans provided data on ICU admission with adjustment for multiple factors, but the pooled analyses

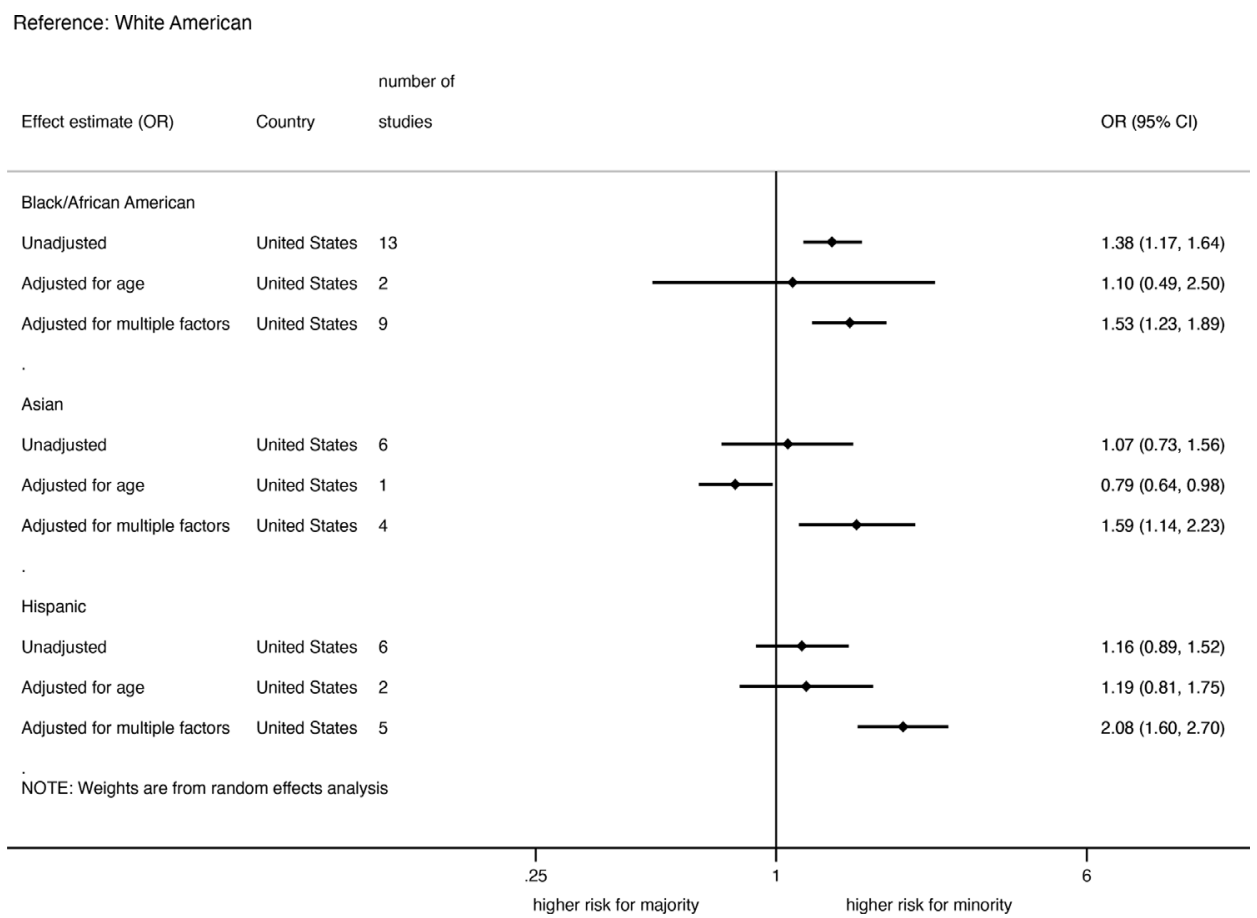

Figure 3 Pooled unadjusted and adjusted risk of hospitalisation among COVID-19-infected patients in the USA. 
Reference: White American

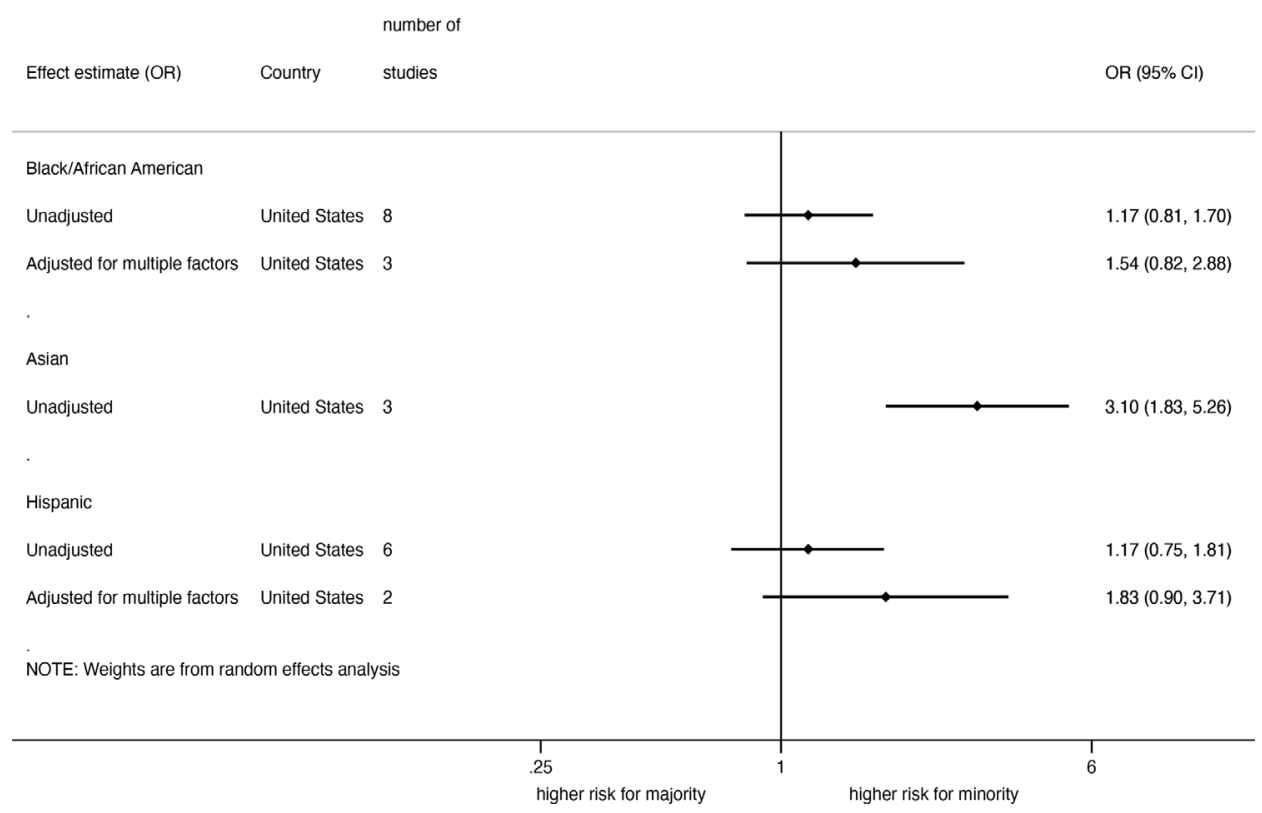

Figure 4 Pooled unadjusted and adjusted risk of severe disease among hospitalised COVID-19-infected patients in the USA.

showed no significant differences between the ethnic groups (online supplemental appendix figure 10).

\section{Death among hospitalised COVID-19 patients}

Studies from USA, Europe and Brazil provided data on ethnic differences in death among hospitalised COVID-19 patients. For the US studies, the summary of pooled unadjusted and adjusted OR for death among hospitalised COVID-19 patients stratified by ethnicity is shown in figure 6 . The pooled unadjusted OR for deaths among hospitalised COVID-19 patients in the
USA was lower in Hispanic-Americans $(0.49 ; 0.37$ to $0.65,5$ studies $)$ and African-Americans $(0.70 ; 0.61$ to $0.81,11$ studies), but not Asian-Americans $(0.91 ; 0.63$ to 1.31, 3 studies) compared with White-Americans (online supplemental appendix figure 11). Three studies on African-Americans, two on Asian-Americans, one each on Hispanic-Americans and Native Hawaiians provided age-adjusted data on the rates of death among hospitalised COVID-19 patients. The pooled age-adjusted ORs showed no significant ethnic differences except for

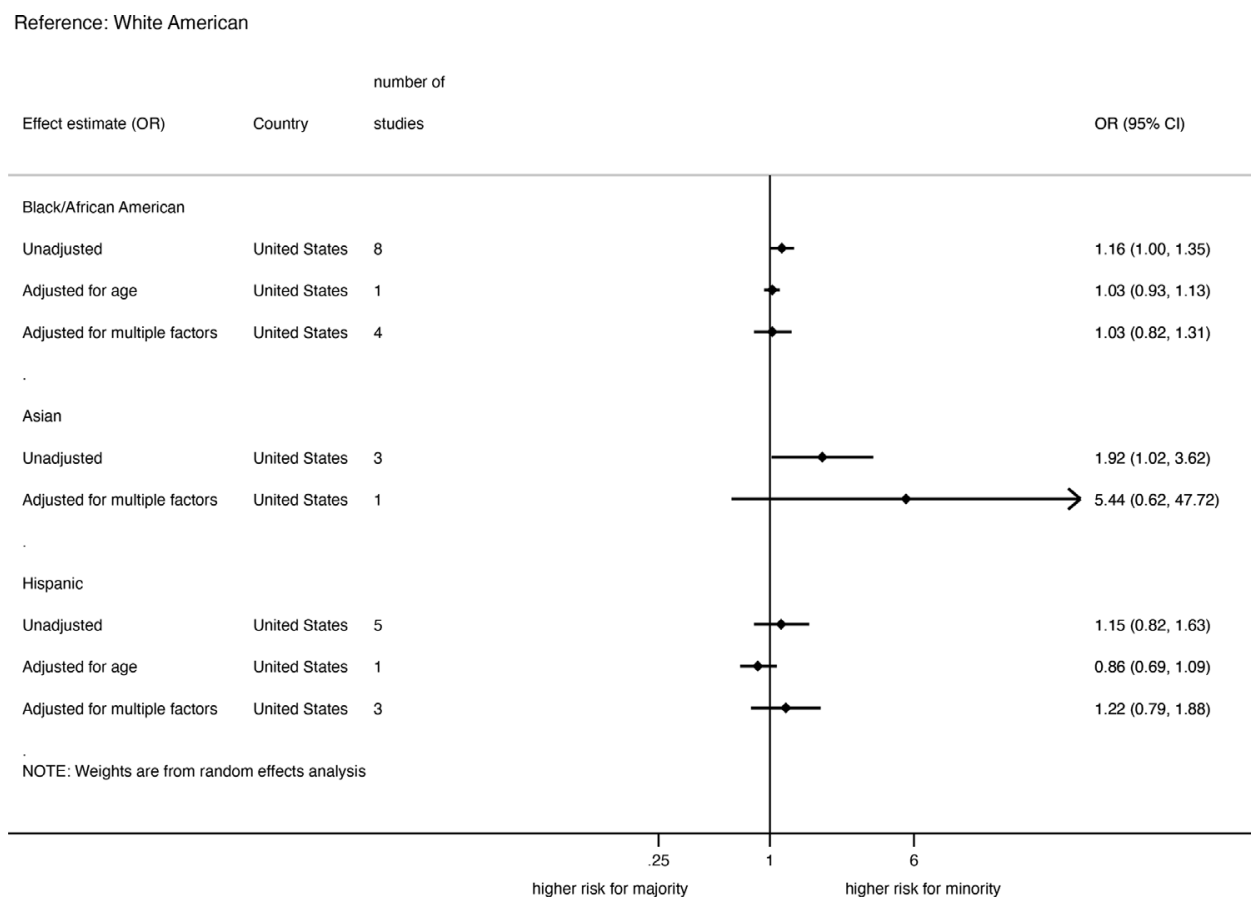

Figure 5 Pooled unadjusted and adjusted risk of ICU admission among hospitalised COVID-19 patients in the USA. 
Reference: White American

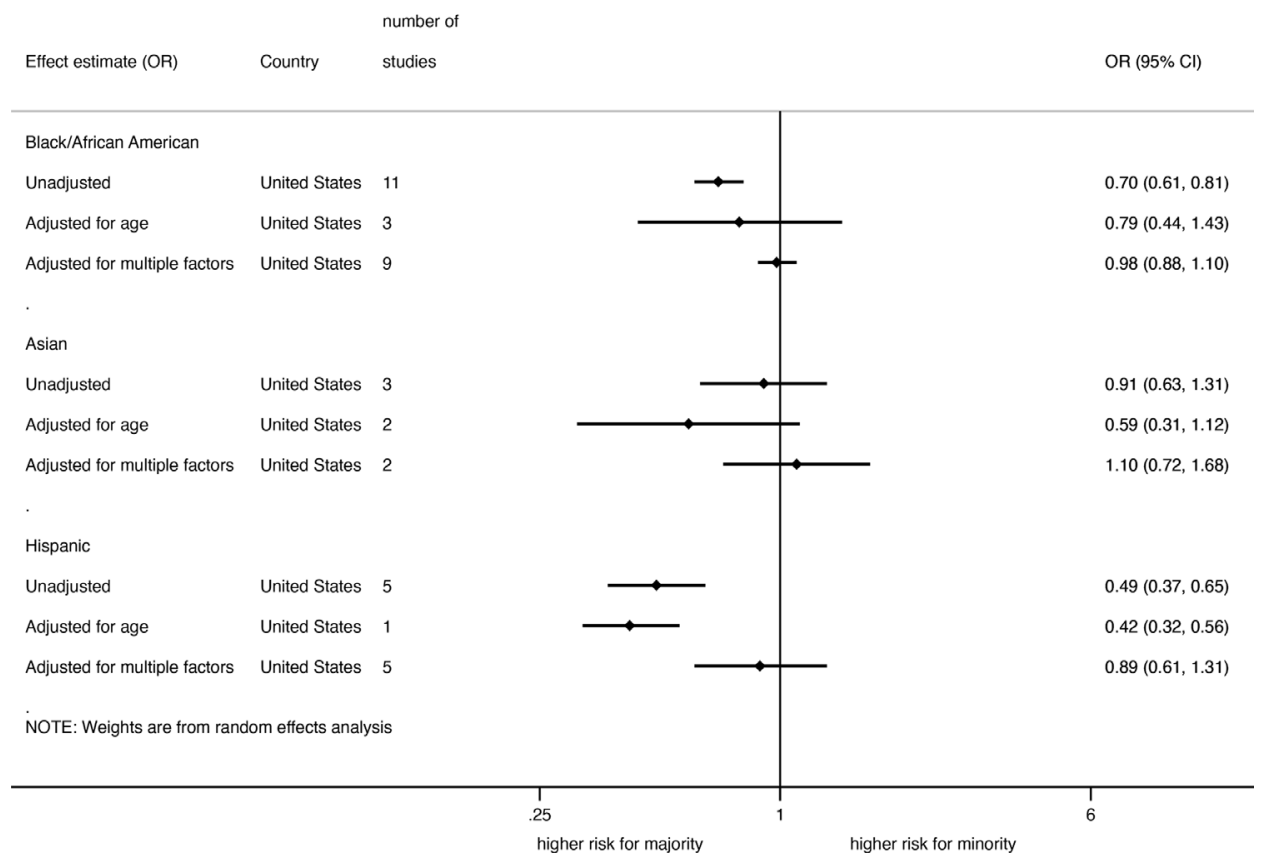

Figure 6 Pooled unadjusted and adjusted risk of death among hospitalised COVID-19 patients in the USA.

lower rate in Hispanic-Americans $(0.42 ; 0.32$ to $0.56,1$ study) compared with White-Americans. Nine studies on African-Americans, 5 studies on Hispanic-Americans and two studies on Asian-Americans provided data with adjustments for multiple factors; and the pooled analysis showed no significant ethnic differences (online supplemental appendix figure 12).

In Europe, four studies on African-Caribbeans/BlackAfricans, four studies on Asians, two studies on SouthAmericans (Hispanics), one study each on South-Asians and Arabs and four studies on Mixed-race provided unadjusted effect estimates on death among hospitalised COVID-19 patients. The pooled unadjusted data stratified by ethnicity are shown in online supplemental appendix figure 13. The risk of death did not differ between the ethnic groups except for the significantly lower for risk for Hispanics (0.31; 0.19 to 0.48$)$ and South-Asians (0.68; 0.54 to 0.86 ) compared with Whites.

In Brazil, two studies on Afro-Brazilians, one on Indigenous and one on East-Asians provided unadjusted effect estimates on death from COVID-19 in hospitalised patients. The analysis showed a higher risk of death among Afro-Brazilians (1.56; 1.10 to 2.22) and East-Asians (1.45; 1.04 to 2.02$)$, but not among Indigenous (1.78; 0.64 to 4.91 ) compared with White Brazilians (online supplemental appendix figure 14). One study provided data with adjustment for multiple factors on risk of death among Afro-Brazilian, mixed-race Brazilian and EastAsian Brazilian hospitalised patients and found a significantly higher risk of death in Afro-Brazilians (1.32; 1.15 to 1.52$)$ and mixed-race Brazilians (1.45, 1.33 to 1.58$)$ compared with White-Brazilians.

\section{Discussion}

Key findings

The risk of confirmed SARS-CoV-2 infection was higher in African-Americans, Hispanic-Americans and AsianAmericans in the USA and in African-Caribbeans/BlackAfricans, South-Asians, Mixed-race people in Europe, compared with their respective White peers. These differences were also significant after adjustment for confounders and explanatory factors in the US ethnic minorities and in African-Caribbeans/Black-Africans in Europe. African-Americans and Hispanic-Americans were also more likely than White-Americans to be hospitalised with SARS-CoV-2 infection even after adjustment for other factors. The outcomes subsequent to hospitalisation (ie, severe disease, ICU admission and death among hospitalised patients) did not differ between the ethnic groups in the USA, except for Asian-Americans for severe disease (higher risk) and for African-American and Hispanics for death (lower risk when unadjusted). In Brazil, Afro-Brazilians and East-Asians had higher risks of death compared with Whites.

\section{Discussion of the key findings}

The disproportionately high risk of confirmed SARSCoV-2 infection in some ethnic groups in both USA and Europe have been attributed to several factors, most of which have their roots in social determinants of health. ${ }^{11819}$ Ethnic minorities are often congregated to the lower end of the socioeconomic ladder leading to over-representation in front line essential jobs in health and social care, retail, public transport and other sectors, which make them more exposed to the public and consequently higher risk of SARS-CoV-2 infection. In 
addition, individuals from ethnic minority backgrounds more often reside in poor neighbourhoods characterised by high crime rates, poor access to healthy foods and crowed housing with sometimes multiple generations or different families living under the same roof mainly due to low SES. Such enclosed and crowded environments facilitate the spread of SARS-CoV-2 infection as social distancing and self-isolation may not be possible in these environments. ${ }^{20}$ Indeed, adjustment for age, sex, comorbidities and SES and other relevant factors yielded increased risk estimates of infection in AfricanAmerican, Asian-Americans and Hispanic-Americans, suggesting that such factors play a disadvantageous role among minorities. However, social and economic circumstances of ethnic minorities may not be well captured by our socioeconomic indicators such as education, income and employment, suggesting considerable residual confounding and underestimation of increased risks for ethnic minorities. ${ }^{18}$ Moreover, public health messaging to prevent SARS-CoV-2 infection might be less effective in ethnic minorities due to language barriers, misinformation and lack of trust in public officials. ${ }^{1}$ These findings clearly suggest the need for further studies to identify key specific social determinants of health that contribute to the high risk of confirmed SARS-CoV-2 infection in some ethnic groups to facilitate prevention and treatment efforts.

The higher rates of hospitalisation with COVID-19 among African-Americans and Hispanic-Americans in the USA are consistent with their higher rates of confirmed SARS-CoV-2 infection. In addition, increased rates have been linked with poor access to primary healthcare, or delay in seeking healthcare ${ }^{21}$ and high rates of preexisting chronic conditions. ${ }^{18} 22-28$ In the USA, AfricanAmericans and Hispanic-Americans are less likely to have health insurance, with consequent reduced healthcare access and use. ${ }^{18} 29$ This might have resulted in higher rates of hospitalisation due to late presentation. Preexisting chronic conditions such as diabetes and hypertension are more common among African-Americans and Hispanic-Americans than the White population, which may contribute to the higher rate of hospitalisation..$^{30} 31$ It has been demonstrated that the risk of hospitalisation with COVID-19 is higher in individuals with pre-existing chronic conditions than those without. ${ }^{29}$

It is well established that ethnic minority groups in the USA and the UK have a higher risk of death from the COVID-19 disease than their White counterparts in the general population. ${ }^{52}$ The UK's ICNARC report also showed that people from ethnic minority background were over-represented in the ICU. ${ }^{2}$ In our current metaanalysis, there were no ethnic differences in the risk of COVID-19 severity and ICU admission among hospitalised patients except for Asian-Americans in the USA. Furthermore, there was no increased risk of death among hospitalised ethnic minority patients relative to the White population except for ethnic minority groups in Brazil. Even Asian-Americans who had a higher risk of
COVID-19 severity and subsequent ICU admissions, had a lower age-adjusted risk of death than White-Americans in the USA for reasons that are not yet unclear. Similar picture was observed for the risk of death among hospitalised COVID-19 patients in Europe where the unadjusted risk of death was lower in hospitalised South-Asians and Hispanics and no differences between Whites and other ethnic groups.

The contrast between our findings of no difference in most ethnic groups or even reduced risk of death among hospitalised patients and that of reported higher risk of death in ethnic minorities in the general population can be attributed to two mechanisms: first of all, the studied outcomes occur sequentially among patients. We considered risks of severe disease, ICU admission and death among hospitalised patients. If specific ethnic groups have an increased risk of getting infected, and subsequently an increased risk of getting hospitalised with SARS-CoV-2 infection, but once hospitalised no increased risk of death, then the overall population of that group still is at increased risk of dying of COVID-19 among the general population. Second, high risk of death reported among ethnic minorities in the general population might be driven by multiple factors such as lack of or inadequate health insurance and consequent limited access to care, which may lead to deaths at home. ${ }^{33}$ Our findings of no increased risk of death among hospitalised ethnic minority patients with COVID-19 thus suggests a clear need to eliminate the potential factors that may prevent their access to healthcare.

Several ethnic minority hospitalised patients in Brazil had an increased risk of death compared with their White Brazilian counterparts. The high risk of death among the Brazilian ethnic minority groups has been pointed to poor access to high quality care driven by unfavourable social determinants of health in ethnic minorities in Brazil. ${ }^{34}$

\section{Strengths and limitations}

Our analyses were based on data from four continents and included only peer-reviewed published papers, whereas earlier works included large number of preprint papers. Additionally, we strived to provide data on the various heterogeneous ethnic groups where possible, and stratified our analyses according to the context, which ethnic minority groups live rather than lumping them together. There are also limitations to our meta-analysis. Large number of the included studies were based on crude unadjusted estimates making comparability somewhat difficult due to potential confounding effect of age and other sociodemographic factors, which might vary between the ethnic groups. Furthermore, although our meta-analyses yielded data from several regions in the world, most of the work were carried out in the USA and Europe (especially UK) with only few studies carried out in South America (only in Brazil) and Asia (only in Thailand and Singapore) and no studies from Africa. This makes extrapolation of our findings to these world 
regions difficult. Though we pooled data for specific ethnic groups where feasible, this was not possible for studies that used broad ethnic categories such as Asians, which is comprised of several ethnic groups with different sociocultural and economic backgrounds making interpretation of the results difficult. Finally, data up to August 2020 were taken into account. With availability of vaccines in many countries, the absolute risks among the general population of most of the studied COVID-19 outcomes will change over time.

\section{CONCLUSION}

In conclusion, the risk of confirmed SARS-CoV-2 infection was higher in most ethnic minority groups than their White counterparts in North American and Europe with the differences remaining in the US ethnic minorities after adjustment for other factors. African-Americans and Hispanic-Americans were also more likely than WhiteAmericans to be hospitalised with SARS-CoV-2 infection. In spite of the high risk of infection, hospitalisation and severity in some ethnic minority groups, there was no increase in the risk of death among ethnic minority patients once hospitalised except for increased risk in ethnic minority groups in Brazil.

These data support the notion that ethnic minority status is an important social determinant of COVIDrelated health outcomes, likely through association with other social determinants including housing, employment situation, SES, general health status and extended effects of racism. These findings suggest the need for further research to understand the broader social determinants of health including housing, work and social structures that produce these inequalities to facilitate COVID-19 prevention and access to healthcare. Additionally, these conclusions should be taken into account in policies aimed at mitigating the ongoing pandemic, especially since global vaccination rates are still suboptimal.

\footnotetext{
Author affiliations

'Department of Public and Occupational Health, Amsterdam Public Health Research Institute, Amsterdam UMC, University of Amsterdam, Amsterdam, The Netherlands ${ }^{2}$ Department of Research and Development, The Netherlands Comprehensive Cancer Organisation, Utrecht, The Netherlands

${ }^{3}$ Department of Methodology and Statistics, Care and Public Health Research Institute (CAPHRI), Maastricht University, Maastricht, The Netherlands

${ }^{4}$ School of Health Professions Education (SHE), Maastricht University, Maastricht, The Netherlands

${ }^{5}$ School of Mental Health and Neuroscience (MHeNS), Maastricht University, Maastricht, The Netherlands

${ }^{6}$ Real World Evidence, UCBPharma, Breda, The Netherlands

${ }^{7}$ Department of Complex Genetics and Epidemiology, Maastricht University, Maastricht, The Netherlands

${ }^{8}$ Department of Epidemiology \& Biostatistics, School of Public Health, Nanjing, People's Republic of China

${ }^{9}$ Department of Orthopaedics, Leiden University Medical Center, Leiden, The Netherlands

${ }^{10}$ Department of Infectious Diseases, Amsterdam Infection and Immunity (All), Amsterdam UMC, University of Amsterdam, Amsterdam, The Netherlands

${ }^{11}$ Department of Infectious Diseases, Research and Prevention, Public Health Service (GGD) of Amsterdam, Amsterdam, The Netherlands
}

${ }^{12}$ Care and Public Health Research Institute (CAPHRI), Maastricht University, Maastricht, The Netherlands

Acknowledgements We thank Anique Atherley, Raissa Derckx, Janna Dijkstra, Gregor Franssen and Annemarie Venemans-Jellema for their work on the literature search and initial screening and extracting phase.

Contributors MPZ conceived the study. Authors AR, SJ, SH, SZ, EY, BP and MPZ were involved in the study design and progress during weekly meetings. GF (acknowledgements only) designed and performed the search strategy. The review team who performed the screening and data extraction consisted of AR, SJ, SH, SZ, EY, BP, MPZ, AA (acknowledgements only), RD (acknowledgements only), JD (acknowledgements only) and AV-J (acknowledgements only). SJ analysed the data. CA and AR wrote the first draft. All authors revised this draft for critical content. All authors approve the final manuscript. MPZ, BP and SJ are the guarantors. All persons listed as authors have contributed to preparing the manuscript and the International Committee of Medical Journal Editors criteria for authorship have been met. All persons other than the authors listed that have contributed significantly to the preparation of the manuscript are listed in the acknowledgements of the manuscript. All authors had full access to all the data in the study and had final responsibility for the decision to submit for publication.

Competing interests None declared.

Patient and public involvement statement Study participants or the public were not involved in the design, or conduct, or reporting or dissemination plans of our research.

\section{Patient consent for publication Not required.}

Ethics approval This is a meta-analysis, no human participants were used directly in this study.

Provenance and peer review Not commissioned; externally peer reviewed.

Data availability statement Data are available upon reasonable request.

Supplemental material This content has been supplied by the author(s). It has not been vetted by BMJ Publishing Group Limited (BMJ) and may not have been peer-reviewed. Any opinions or recommendations discussed are solely those of the author(s) and are not endorsed by BMJ. BMJ disclaims all liability and responsibility arising from any reliance placed on the content. Where the content includes any translated material, BMJ does not warrant the accuracy and reliability of the translations (including but not limited to local regulations, clinical guidelines, terminology, drug names and drug dosages), and is not responsible for any error and/or omissions arising from translation and adaptation or otherwise.

Open access This is an open access article distributed in accordance with the Creative Commons Attribution Non Commercial (CC BY-NC 4.0) license, which permits others to distribute, remix, adapt, build upon this work non-commercially, and license their derivative works on different terms, provided the original work is properly cited, appropriate credit is given, any changes made indicated, and the use is non-commercial. See: http://creativecommons.org/licenses/by-nc/4.0/.

\section{ORCID iDs}

Anke Richters http://orcid.org/0000-0002-1580-1543

Bart Pijls http://orcid.org/0000-0001-5351-5057

\section{REFERENCES}

1 Bhala N, Curry G, Martineau AR, et al. Sharpening the global focus on ethnicity and race in the time of COVID-19. Lancet 2020;395:1673-6.

2 ICNARC. Intensive care national audit and research centre INARC report on COVID-19 in critical care, 2020. Available: https://www. icnarc.org/

3 Williamson EJ, Walker AJ, Bhaskaran $\mathrm{K}$, et al. Factors associated with COVID-19-related death using opensafely. Nature 2020:584:430-6.

4 Artiga S, Garfield R, Orgera K. Communities of color at higher risk for health and economic challenges due to COVID-19. San Francisco, CA, 2020.

5 Prevention UCfDCa. COVID-19 in racial and ethnic minority groups, 2020. Available: https://www.cdc.gov/coronavirus/2019-ncov/ community/health-equity/race-ethnicity.html

6 Sze S, Pan D, Nevill CR, et al. Ethnicity and clinical outcomes in COVID-19: a systematic review and meta-analysis. EClinicalMedicine 2020;29:100630. 
7 Raharja A, Tamara A, Kok LT. Association between ethnicity and severe COVID-19 disease: a systematic review and meta-analysis. $J$ Racial Ethn Health Disparities 2020:1-10.

8 Moher D, Liberati A, Tetzlaff J, et al. Preferred reporting items for systematic reviews and meta-analyses: the prisma statement. PLoS Med 2009;6:e1000097.

9 Pijls BG, Jolani S, Atherley A, et al. Demographic risk factors for COVID-19 infection, severity, ICU admission and death: a metaanalysis of 59 studies. BMJ Open 2021;11:e044640.

10 World Health Organization. Clinical management of severe acute respiratory infection when novel coronavirus (2019-nCoV) infection is suspected: interim guidance, 28 January 2020, 2020. Available: https://apps.who.int/iris/handle/10665/330893

11 Wells GA, Shea B, Da O'Connell. The Newcastle-Ottawa scale (NOS) for assessing the quality of nonrandomised studies in meta-analyses. Oxford, 2000.

12 DerSimonian R, Laird N. Meta-analysis in clinical trials. Control Clin Trials 1986;7:177-88.

13 Dekkers OM, Vandenbroucke JP, Cevallos M, et al. COSMOS-E: guidance on conducting systematic reviews and meta-analyses of observational studies of etiology. PLoS Med 2019;16:e1002742.

14 Bhopal R, Unwin N, White M, et al. Heterogeneity of coronary heart disease risk factors in Indian, Pakistani, Bangladeshi, and European origin populations: cross sectional study. BMJ 1999;319:215-20.

15 Egger M, Davey Smith G, Schneider M, et al. Bias in meta-analysis detected by a simple, graphical test. BMJ 1997;315:629-34.

16 Harbord RM, Egger M, Sterne JAC. A modified test for small-study effects in meta-analyses of controlled trials with binary endpoints. Stat Med 2006;25:3443-57.

17 Soares RdeCM, Mattos LR, Raposo LM. Risk factors for hospitalization and mortality due to COVID-19 in Espírito Santo state, Brazil. Am J Trop Med Hyg 2020;103:1184-90.

18 Yancy CW. COVID-19 and African Americans. JAMA 2020:323:1891-2.

19 England $\mathrm{PH}$. Review into factors impacting health outcomes from COVID-19, 2020. Available: https://www.gov.uk/government/news/ review-into-factors-impacting-health-outcomes-from-covid-19

20 Cevik M, Marcus JL, Buckee C, et al. Severe acute respiratory syndrome coronavirus 2 (SARS-CoV-2) transmission dynamics should inform policy. Clin Infect Dis 2021;73:S170-6.

21 Egede LE, Walker RJ. Structural Racism, Social Risk Factors, and Covid-19 - A Dangerous Convergence for Black Americans. N Engl J Med 2020;383:e77.
22 Emami A, Javanmardi F, Pirbonyeh N, et al. Prevalence of underlying diseases in hospitalized patients with COVID-19: a systematic review and meta-analysis. Arch Acad Emerg Med 2020;8:e35.

23 Richardson S, Hirsch JS, Narasimhan M, et al. Presenting characteristics, comorbidities, and outcomes among 5700 patients hospitalized with COVID-19 in the New York City area. JAMA 2020;323:2052-9.

24 Wang B, Li R, Lu Z, et al. Does comorbidity increase the risk of patients with COVID-19: evidence from meta-analysis. Aging 2020;12:6049-57.

25 Petrilli CM, Jones SA, Yang J, et al. Factors associated with hospital admission and critical illness among 5279 people with coronavirus disease 2019 in New York City: prospective cohort study. BMJ 2020;369:m1966.

26 Owen WF, Carmona R, Pomeroy C. Failing another national stress test on health disparities. JAMA 2020;323:1905-6.

27 Corl K, Levy M, Phillips G, et al. Racial and ethnic disparities in care following the New York state sepsis initiative. Health Aff 2019;38:1119-26.

28 Price-Haywood EG, Burton J, Fort D, et al. Hospitalization and mortality among black patients and white patients with Covid-19. N Engl J Med 2020;382:2534-43.

29 Prevention UCfDCa. Health of black or African American nonhispanic population. Available: https://www.cdc.gov/nchs/fastats/ black-health.htm

30 Agyemang C, van den Born B-J. Non-communicable diseases in migrants: an expert review. J Travel Med 2019;26:tay107.

31 Odlum M, Moise N, Kronish IM, et al. Trends in poor health indicators among black and hispanic middle-aged and older adults in the United States, 1999-2018. JAMA Netw Open 2020;3:e2025134.

32 White C, Nafilyan V. Coronavirus (COVID-19) related deaths by ethnic group, England and Wales: 2 March 2020 to 15 may 2020 , 2020. Available: https://www.ons.gov.uk/peoplepopulationandc ommunity/birthsdeathsandmarriages/deaths/articles/coronavirusr elateddeathsbyethnicgroupenglandandwales/2march2020to10ap ril2020

33 Ogedegbe G, Ravenell J, Adhikari S, et al. Assessment of racial/ ethnic disparities in hospitalization and mortality in patients with COVID-19 in New York City. JAMA Netw Open 2020;3:e2026881.

34 Baqui P, Bica I, Marra V, et al. Ethnic and regional variations in hospital mortality from COVID-19 in Brazil: a cross-sectional observational study. Lancet Glob Health 2020;8:e1018-26. 